\title{
Effect of moderate exercise on the ocular tension
}

\author{
D. A. LEIGHTON AND G. I. PHILLIPS
}

Department of Ophthalmology, University of Manchester, and Manchester Royal Eye Hospital

A few studies on the effects of hard or prolonged exercise on the ocular tension have reported a fall, except for the immediate rise which occurs on contraction of the abdominal and thoracic muscles (Comberg and Stoewer, 1925) or on the performance of the Valsalva manoeuvre (Biró and Botár, 1962). Short (100 m.) and middle distance ( $1,000 \mathrm{~m}$. ) running was associated with a fall, greater with the longer distance (Biró and Botár, 1962). However, after a $50 \mathrm{~km}$. route march by 142 soldiers, 65.2 per cent. showed a rise, 15.7 per cent. a fall, and I9.I per cent. no change (Kern, 1964). After severe exercise to exhaustion, Lempert, Cooper, Culver, and Tredici ( 1967 ) found a consistent fall in ocular tension.

In the present investigation, the effects on the ocular tension of walking (a more moderate type of exercise than those mentioned above) and sitting are compared.

\section{Subjects and method}

Fourteen healthy young adults, 12 males and 2 females, aged 21 to 35 years, were treated on two consecutive mornings in the following way:

(I) “EXERGISE'" MORNING

(a) Applanation tensions recorded from both eyes.

Subjects sat in a library for 50 minutes.

(b) Applanation tensions repeated.

Subjects walked briskly for 50 minutes.

(c) Applanation tensions repeated immediately after end of exercise.

(2) "RESTING" MORNING

(a) Applanation tensions recorded from both eyes.

Subjects sat in a library for 50 minutes.

(b) Applanation tensions repeated.

Subjects sat in a library for a further 50 minutes.

(c) Applanation tensions repeated.

In seven of the fourteen subjects the blood pressure was measured from the brachial artery (right arm in every case), using a sphygmomanometer cuff immediately after each applanation tension, $(a)$, $(b)$, and $(c)$ above, had been recorded on each morning of the investigation.

The order in which subjects were exercised or rested was randomized so that, of the fourteen subjects, seven exercised on day (I) and rested on day (2) and seven rested on day (I) and exercised on day (2).

Each phase of the investigation was carried out at the same time of the day on exercise and resting days. A technician recorded the ocular tensions using a Goldmann applanation tonometer. The 
tension was always measured first from the right eye and then from the left. The measurements of the blood pressure were made by one of us (DAL).

\section{Results}

Changes in ocular tension which occurred after walking and sitting are recorded in Table I as differences between the second $(b)$ and third $(c)$ applanation readings, that is immediately before and after walking on the exercise day, and immediately before and after sitting in the library for the second period on the resting day.

Table I Effect of walking compared with sitting on the ocular tension in fourteen subjects

\begin{tabular}{|c|c|c|c|c|c|c|}
\hline \multirow{3}{*}{$\begin{array}{l}\text { Subject } \\
\text { no. }\end{array}$} & \multicolumn{6}{|c|}{ Change in applanation tension $(\mathrm{mm} . \mathrm{Hg})$} \\
\hline & \multicolumn{3}{|l|}{ Right eyes } & \multicolumn{3}{|l|}{ Left eyes } \\
\hline & * Walking & $\stackrel{+}{\text { Sitting }}$ & $\begin{array}{l}\text { * } \\
\text { Net change } \\
\text { (Walking-Sitting) }\end{array}$ & Walking & $\begin{array}{l}\dagger_{\text {Sitting }} \\
\text { Sing }\end{array}$ & $\begin{array}{l}\text { * } \\
\text { Net change } \\
\text { (Walking-Sitting) }\end{array}$ \\
\hline $\mathbf{I}$ & -1 & $+I$ & -2 & $-I$ & +1 & -2 \\
\hline 2 & -4 & o & -4 & -3 & $-I$ & -2 \\
\hline 3 & $-I$ & -2 & $+I$ & -2 & -2 & o \\
\hline 4 & -2 & -2 & $\mathbf{o}$ & -3 & $\mathbf{o}$ & -3 \\
\hline 5 & -8 & -3 & -5 & -5 & $\mathbf{o}$ & -5 \\
\hline 6 & -2 & +3 & -5 & -4 & +2 & -6 \\
\hline 7 & -2 & +3 & -5 & -3 & +4 & -7 \\
\hline 8 & $-I$ & $+I$ & -2 & o & +1 & $-I$ \\
\hline 9 & -3 & +1 & -4 & $-I$ & $-I$ & o \\
\hline 10 & -3 & $-I$ & -2 & -2 & -2 & $\mathbf{o}$ \\
\hline I I & $+I$ & o & +1 & o & $+I$ & $-I$ \\
\hline 12 & o & $-\mathbf{I}$ & $+I$ & $\mathbf{o}$ & $+\mathbf{I}$ & $-I$ \\
\hline 13 & $-I$ & -2 & $+I$ & -2 & -2 & 0 \\
\hline 14 & -5 & $-I$ & -4 & -3 & 0 & -3 \\
\hline
\end{tabular}

Numbers in columns headed "walking" and "sitting" for right and left eyes refer to differences between applanation tensions recorded immediately before $(b)$ and after $(c)$ walking and sitting. A minus sign denotes a fall and a plus sign a rise. "Net Change" refers to the difference between the change after walking and that after sitting. A minus sign, for example, indicates that a fall after walking had been greater than a fall after sitting, and a plus sign, for example, that a fall after sitting had been greater than a rise after walking

* significant fall found in ocular tension when Wilcoxon test was used $(P<0.01)$ in each case + no significant change found in ocular tension

\section{(i) Effect of walking and sitting on ocular tension}

The Wilcoxon Matched Pairs Signed Ranks test (Siegel, 1956) was used to analyse these changes in ocular tension. The fall which occurred after walking was found to be statistically significant $(\mathrm{P}<0.0 \mathrm{I})$ for both eyes, but no significant change in ocular tension occurred after sitting.

(ii) Net change in ocular tension due to walking (i.e. subtracting "sitting" change used as control)

If the change in tension after sitting be regarded as the underlying trend of ocular tension during that period in the morning (i.e. the change after sitting being in the nature of a 
control) on which the change produced by walking is superimposed, then a "net" change (i.e. walking change minus sitting change) should be considered. The Wilcoxon test showed that there had been a significant fall $(P<0 \cdot 0 \mathrm{r})$ in both eyes for walking compared with sitting.

The mean applanation tensions immediately before and after walking and sitting (readings $(b)$ and $(c)$ for right and left eyes) and the mean changes in tension corresponding to these are seen in Table II, and as bar charts in Fig. I. Student's " $t$ " test was used to

Table II Mean applanation tensions $(\mathrm{mm} . \mathrm{Hg}$ ) in fourteen subjects immediately before and after walking and sitting, and the differences between them

\begin{tabular}{|c|c|c|c|c|c|c|c|c|}
\hline Eyes & Right & & & & Left & & & \\
\hline Reading & Initial & Final & Difference & $P$ & Initial & Final & Difference & $P$ \\
\hline Walking & $14 \cdot 07$ & II $\cdot 79$ & $\begin{array}{l}\text { (fall) } \\
2 \cdot 28\end{array}$ & $<0.01 *$ & $13 \cdot 64$ & $11 \cdot 57$ & $\begin{array}{l}\text { (fall) } \\
2 \cdot 07\end{array}$ & $<0.01 *$ \\
\hline Sitting & $14 \cdot 14$ & $14 \cdot 00$ & $\begin{array}{l}(\text { fall }) \\
0 \cdot 14\end{array}$ & $>0.05 \dagger$ & 13.07 & 13.21 & $\begin{array}{l}\text { (rise) } \\
0 \cdot 14\end{array}$ & $>0.05 t$ \\
\hline $\begin{array}{l}\text { Difference } \\
\text { (Walking - Sitting) }\end{array}$ & 0.07 & $2 \cdot 21$ & $2 \cdot 14$ & $<0.01 *$ & 0.57 & $I \cdot 64$ & $2 \cdot 21$ & $<0.0 I^{*}$ \\
\hline
\end{tabular}

* Significant at a level of less than I per cent.

† Not significant at a level of more than 5 per cent. (Student's " $t$ " test was used to estimate P)

\section{EFFECT OF WALKING}

RIGHT EYES

$\begin{array}{lllll}\text { MEAN } & 14.07 & 11.79 & 13.64 & 11.57 \\ \text { DIFF } & \text { FALL } & 2.28 * & \text { FALL } & 2.07 *\end{array}$

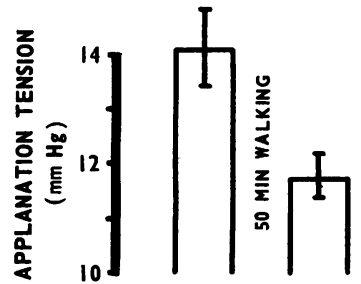

EFFECT OF SITTING

RIGHT EYES

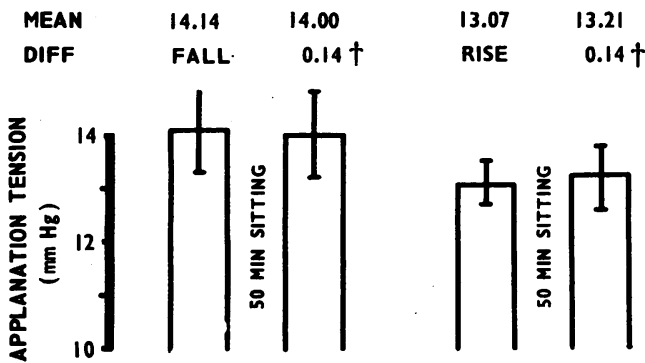

FIG. I Bar charts, showing mean applanation tensions ( $\mathrm{mm} . \mathrm{Hg}$ ) in fourteen subjects immediately before and after:

$$
\begin{aligned}
& \text { ABOVE } 50 \text { minutes walking } \\
& \text { BELOW } 50 \text { minutes sitting }
\end{aligned}
$$

The standard error of the mean is indicated on each bar

*Significant at $P<0.01$ using both the Wilcoxon test and Student's " $t$ " test.

†Not significant by either of these tests. 
estimate the significance of these changes and gave results which agreed with those recorded above when the Wilcoxon test was used, i.e. a fall $(\mathrm{P}<0 \cdot 0 \mathrm{I})$ appeared after exercise in $\frac{\omega}{3}$

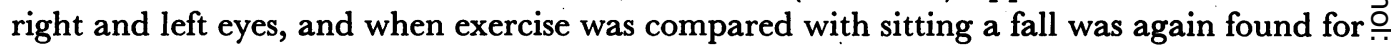
right and left eyes, significantly greater for walking than sitting $(P<0.01)$; the change $\vec{F}$ which followed sitting was not significant $(P>0 \cdot 05)$.

\section{(iii) Effect of initial ocular tension}

Fig. 2 shows that the magnitude of the fall in ocular tension which resulted from walking $\stackrel{\triangle}{\triangle}$ was dependent on the height of the ocular tension before walking. The Spearman Rank Correlation method (Siegel, I956) showed a significant correlation between them (right $\vec{\circ}$ eyes $0.01<\mathrm{P}<0.05$; left eyes $\mathrm{P}<0.01$; correlation coefficients $+0.62 \mathrm{I}$ and +0.788 respectively).

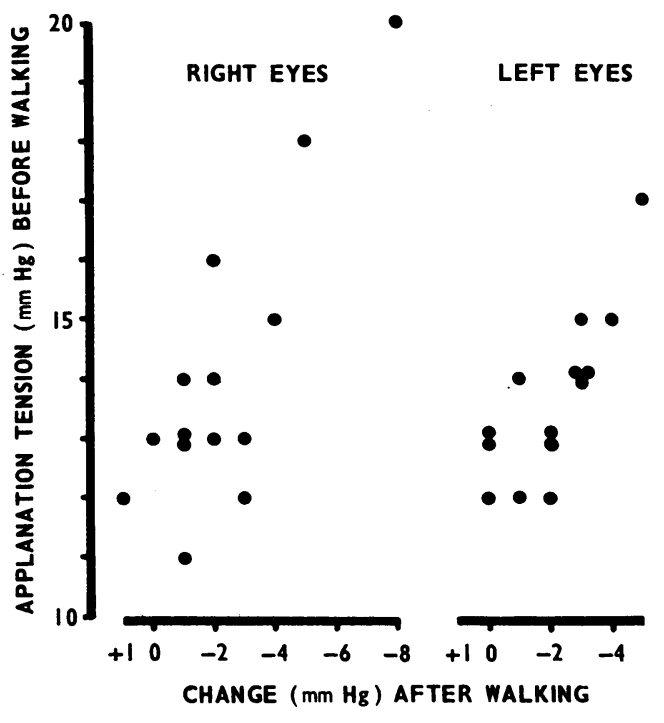

FIG. 2 Graph of ocular tension in fourteen subjects:

(1) immediately before walking

(2) change which followed walking

A significant correlation between $I$ and 2 was present:

Right eyes $0.01<\mathrm{P}<0.05$

Left eyes $\mathbf{P}<0.01$

Correlation coefficients were +0.621 and +0.788 respectively

\section{(iv) Importance of randomization}

The effect of randomization can be seen in Fig. 3 (opposite), which shows bar charts of the mean initial $(a)$ and second $(b)$ applanation tensions which had been recorded on the two consecutive days, viz.:

I: $\quad$ Not in randomized order, i.e. tensions taken on Day I and Day 2;

II : In randomized order, i.e. tensions taken from seven subjects on Day I and from seven on Day 2.

The mean ocular tensions for Day I are in every case noticeably higher than those for Day 2. It is surprising that this trend is more marked in applanation readings $(b)$ i.e. "second readings" than in the "initial readings" (a) (see Fig. 3). The object of the $(a) \circlearrowleft$ readings was to accustom the subjects to tonometry, but as it turned out these readings would have constituted a more uniform baseline than the $(b)$ readings. However, as Fig. $3 \stackrel{?}{7}$ clearly shows, randomization has tended to equalize mean ocular tensions before walking and sitting, and has therefore improved the reliability of the results. Only in readings 
INITIAL READING

NOT RANDOMIZED

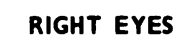

DAY I DAY 2

DIFFERENCE $-0.65 \uparrow$
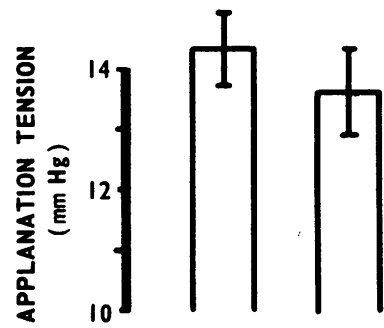

STRICTLY RANDOMIZED

RIGHT EYES

WALKING SITTING

DIFFERENCE + $0.07+$
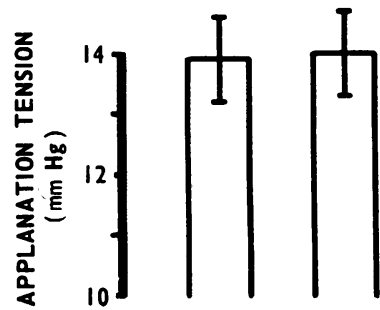

LEFT EYES

DAY I DAY 2

DIFFERENCE $-0.29 \dagger$

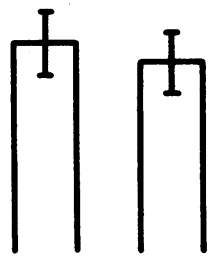

LEFT EYES

WALKING SITTING

DAY

DAY

DIFFERENCE - $0.14+$
SECONDREADING

NOT RANDOMIZED

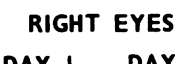

DAY I DAY 2

DIFFERENCE $-0.86 \dagger$
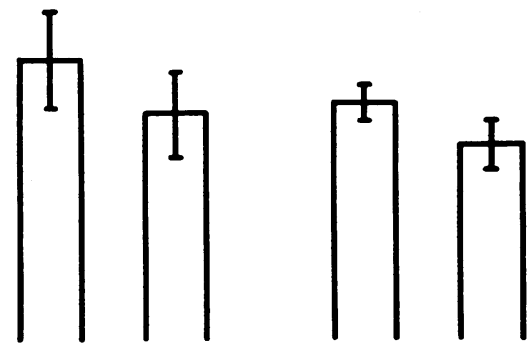

STRICTLY RANDOMIZED
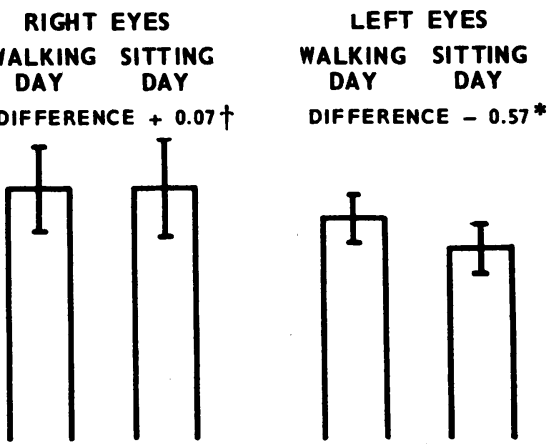

LEFT EYES

DAY I DAY 2
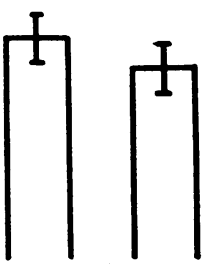

DIFFERENCE - 0.71 **

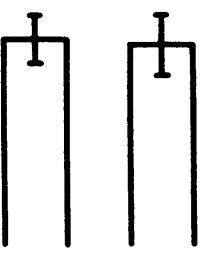

FIG. 3 Bar charts showing effect of randomization on mean ocular tension (mu. $\mathrm{Hg}$ ) in fourteen subjects (i.e. a comparison of mean initial (a) and second (b) ocular tensions):

ABOVE Without randomization, i.e. those recorded on Day I and Day 2

BELOw Strictly randomized, i.e. for the walking day and the sitting day, either of which would have been Day I for seven subjects and Day 2 for seven subjects

The standard error of the mean is indicated on each bar

** difference significant at $0.01<P<0.02$ using the Wilcoxon test and Student's " $t$ " test

* difference not significant using the Wilcoxon test $(P>0.05)$ but significant using Student's " $t$ " test $(0.02<\mathrm{P}<0.05)$

$\dagger$ difference not significant by either test

(b) for left eyes was the randomization relatively ineffective in equalizing mean ocular tensions $(b)$ before exercise and rest, i.e.

$$
\begin{array}{lll}
\text { Day I - Day } 2 & \text { mean fall } 0.71 \mathrm{~mm} . \\
\text { Walking day - Sitting day: } & \text { mean fall } 0.57 \mathrm{~mm} .
\end{array}
$$

It has already been shown (see Fig. 2) that the magnitude of the fall in ocular tension that occurred with walking was dependent on the height of the tension before walking. 
If there had been a tendency for the ocular tension to fall in left eyes during sitting, this might have been masked by the relatively low ocular tension before sitting. In fact a slight rise in ocular tension was found in this case and the result was probably not seriously affected. However, if no randomization had been carried out and, say, all fourteen subjects had exercised on Day I, then the mean pre-walking tension $(b)$ on Day I, which would be expected to be higher than the mean pre-sitting tension $(b)$ on Day 2, would have biased the results in favour of a greater fall after walking than after sitting. Accordingly, without randomization, the validity of a fall in ocular tension which followed walking would have been open to some doubt. Leighton, Phillips, and Gibbs (1970), in a series of three provocative outflow tests on 24 subjects, showed that uniform pre-provocation values could be obtained by strict randomization in the order of performance of the tests.

Fig. I shows that the mean ocular tension was consistently lower in left than in right eyes. However, tension was consistently measured first in right eyes so that, in the absence of randomization, no validity can be attributed to that observation. Perkins (1959) has commented on this trend.

Mean ocular tensions $(a)$ and $(b)$ were consistently less for Day 2 than for Day I, but this reached "significance" only for tension $(b)$ in left eyes $(0 \cdot 01<\mathrm{P}<0.02)$. Bankes, Perkins, Tsolakis, and Wright (1968) have also commented on this trend.

To sum up, it is likely that a comparison of changes in ocular tension which occurred after $(a)$ walking and $(b)$ sitting, carried out in randomized order at the same time of day on consecutive days, was a more reliable indication of the effect of walking on ocular tension than merely the circumstantial evidence of changes in ocular tension whicla occurred after walking on a particular day, i.e. the ocular tension might have fallen if nQ walking had been done. However, differences between mean tension readings $(b)$ an $(c)$ and between $(a)$ and $(c)$ on the resting day, and readings $(a)$ and $(b)$ on Days $\mathrm{I}$ and $\frac{\overrightarrow{2}}{2}$ were negligible.

No significant rise in the systolic or diastolic blood pressures after walking was found. If the change in blood pressure after sitting was taken into account, there was again no significant rise after walking.

\section{Discussion}

At first sight it might appear surprising that the ocular tension fell after exercise. The expected rise in blood pressure due to exercise might have been paralleled by an increase in ocular tension. However, such a secondary rise would probably be very transient (Duke-Elder, 1968) and the rise in blood pressure in the seven subjects in whom it was measured was slight. The systolic blood pressure was, on the average, $8.5 \mathrm{~mm}$. greater after walking than after resting. The exercise was, of course, moderate in severity.

It is known that a rise in ocular tension can result from an increase in the venous pressure (Bain and Maurice, I959; Comberg and Pilz, I96I) by constriction of the neck using an inflatable cuff. The former authors, who used a tonometer which could record the ocular tension constantly, also showed that the ocular tension could be increased by blowing against a column of mercury, coughing, and performing the Valsalva manoeuvre. They also reported a transient fall and then a rise in ocular tension on rising from a crouched (knees bend) position. They suggested that these variations in ocular tension were due to changes in venous and arterial pressure, as well as to gravity. An increase in jugular venous pressure induced in these ways could cause a rise in the episcleral venous pressure, thereby raising the intraocular pressure. 
The explanation of a reduction in ocular tension with walking could be the opposite of this, i.e. a reduction in jugular venous pressure. Compensatory vascular mechanisms might be very effective and prompt, however, in reverting to a status quo. Measurement of the episcleral venous pressure and jugular venous pressure would be required to investigate this point.

However, we consider it quite possible that a fall in ocular tension is effected through an adrenergic or other hormonal mechanism; an effect on electrolytes or electrolyte-transport enzymes may be involved. A rise in pressure is often associated with sleep, which is presumably consistent with the fall on moderate exercise.

It cannot be assumed that, because healthy, normal subjects respond to walking by a reduction in ocular tension, adult patients with open or closed-angle glaucoma will respond similarly. If the explanation for the fall in ocular tension is a haemodynamic one, dependent on a fall in the jugular venous pressure, then the high pressure gradient between the anterior chamber and the episcleral veins in glaucoma would make a reduction in intraocular pressure less likely. On the other hand, a high initial intraocular pressure might be associated, as has been shown above, with a greater fall in intraocular pressure. Patients with glaucoma are to be investigated to see if they too respond to walking with a fall in ocular tension.

It would seem reasonable at present not to discourage patients who have glaucoma from walking; perhaps, on the contrary, it should be encouraged!

\section{Summary}

Fourteen adult subjects undertook walking and sitting for 50 minutes each on two consecutive mornings in randomized order. Walking and the net change produced by walking after an allowance had been made for the expected change attributable to sitting (as determined on a "control" day) both resulted in a significant fall in ocular tension. The change in ocular tension associated with sitting was, however, negligible. The higher the pressure was before walking, the greater was the fall afterwards (significant).

\section{References}

BAIN, W. E. S., and MAURICE, D. M. (1959) Trans. ophthal. Soc. U.K., 79, 249

BANkes, J. L. K., PERkins, E. s., tsolakis, s., and Wright, J. E. (1968) Brit. med. J., I, 791

BIró, I., and botár, F. (1962) Klin. Mbl. Augenheilk., 140, 23

Comberg, D., and PIlz, A. (1961) v. Graefes Arch. Ophthal., 163, I89

COMBerg, w., and stoewer, E. (1925) Z. Augenheilk., 58, 92

DUKE-ELdER, s. (1968) "System of Ophthalmology", vol. 4 "The Physiology of the Eye and of

Vision", p. 287. Kimpton, London

KERN, R. (I964) Ophthalmologica (Basel), I47, 82

LEIGHTON, D. A., PHIllips, c. I., and giBBS, A. c. c. (1970) Brit. 7. Ophthal., 54, I9

LEMPERT, P., COOPER, K. H., CUlver, J. F., and Tredici, T. J. (I967) Amer. J. Ophthal., 63, i673

PERKins, E. S. (1959) In "Glaucoma. Trans. 3rd. Conference, I958”, ed. F. W. Newell, p. I43.

Josiah Macey, Jr., Foundation, New York

MEgeL, S. (1956) "Nonparametric Statistics for the Behavioral Sciences", pp. 75, 202. McGraw-

Hill, New York

stewart, R. H., Le blanc, R., and Becker, B. (1970) Amer. 7. Ophthal., 69, 245

Addendum Since this paper was written similar results have been reported by Stewart, Le Blanc, and Becker (1970). 